\title{
Research Data Management and the Canadian Academic Library: An Organizational Consideration of Data Management and Data Stewardship
}

\author{
Michael Steeleworthy \\ Data Librarian \\ Wilfrid Laurier University \\ msteeleworthy@wlu.ca
}

\begin{abstract}
Research data management (RDM) has become a professional imperative for Canada's academic librarians. Recent policy considerations by our national research funding agencies that address the ability of Canadian universities to effectively manage the massive amounts of research data they now create has helped library and university administrators recognize this gap in the research enterprise and identify RDM as a solution. RDM is not new to libraries, though. Rather, it draws on existing and evolving organizational functions in order to improve data collection, access, use, and preservation. A successful research data management service requires the skills and knowledge found in a library's research liaisons, collections experts, policy analysts, IT experts, archivists and preservationists. Like the library, research data management is not singular but multi-faceted. It requires collaboration, technology and policy analysis skills, and project management acumen.
\end{abstract}

This paper examines research data management as a vital information, technical, and policy service in academic libraries today. It situates RDM not only as actions and services but also as a suite of responsibilities that require a high level of planning, collaboration, and judgment, thereby binding people to practice. It shows how RDM aligns with the skill sets and competencies of librarianship and illustrates how RDM spans the library's organizational structure and intersects with campus stakeholders allied in the research enterprise.

\section{Keywords}

research data management; research; research grants - government policy; big data; library organization; library administration

\section{Introduction}

In October 2013 Canada's national research funding agencies, the Social Sciences and Humanities Research Council (SSHRC), the Natural Sciences and Engineering Research Council (NSERC), The Canadian Institutes of Health Research (CIHR), and the Canada Foundation for Innovation (CFI) released a consultation document that 
addressed the ability of the nation's universities to effectively produce and manage the massive amount of research data it now collects and creates (Social Sciences and Humanities Research Council et al.). Entitled Capitalizing on Big Data: Toward a Policy Framework for Advancing Digital Scholarship in Canada, this document made research data management (RDM) a professional imperative for Canada's academic librarians. As the deluge of digitally born data now cascades into our libraries, research centres, and laboratories, librarians have responded by applying their expertise in information collection, access, use, and preservation to our researchers' project files, data inputs and outputs, and publications. While RDM is not conceptually new to the information profession, its many facets make it difficult to reconcile with common library functions such as collections, reference and research, access services, or metadata management even though it shares methods, practices, and goals with all these areas. This paper will introduce research data management as a vital information, technical, and policy service, show how it aligns with the skills sets and competencies of librarianship, and illustrate the manner in which it spans the library's organizational structure and intersects with stakeholders in the university research enterprise.

\section{Understanding Research Data Management}

Research data management (RDM) is regularly described in terms of a system of people, policy, resources, and technology that support and give direction to researchers and organizations as they produce, collect, use, and preserve research data. Its activities and responsibilities are wide-ranging, a fact that can affect the ways in which RDM professionals emphasize its different elements. Graham Pryor focuses on the core tenets of preservation and use when he describes RDM as "an active process by which digital resources remain discoverable, accessible and intelligible over the longer term" (xi). Michael Witt highlights RDM's multitude of processes when he refers to it as a set of "activities such as assisting researchers formulate funder-required data plans, adapting library practice to help organize and describe research datasets, developing data collections and data repositories, digital preservation, and data literacy" (173). On the other hand, the Canadian Association of Research Libraries (CARL) Data Management Sub-Committee focuses on the data professionals who conduct RDM when they note that "[p]lanning and support from data professions at the initial stages of the research project can significantly reduce the time and money needed to provide long-term access to research data and research outputs" ("Research Data" 4).

Between Pryor, Witt, and CARL, a necessary pairing of people and processes in RDM emerge since the actions required to meet its preservation, sharing, and access goals require a high level of planning, collaboration, and judgement. As Chuck Humphrey shows, the deliberations and actions of the people involved in RDM are intrinsically tied to RDM itself through the concept of data stewardship. He begins by describing RDM strictly in terms of practice:

Research data management involves the practices and activities across the research lifecycle that involve the operational support of data through design, production, processing, documentation, analysis, preservation, 
discovery and reuse. Collectively, these data-related activities span the stages of project-based research as well as the extended stages that tend to be institutionally based. The activities are about the "what" and "how" of research data.

Having established this "what" and "how", Humphrey then turns to the professionals required to put RDM into action:

Data Stewardship is about the identity of those responsible for ensuring data management activities are performed to best practice levels and standards across the lifecycle. Stewardship addresses "who" is responsible for a specific data activity ... Data policies, institutional norms, granting council requirements, and domain practices all contribute to defining the roles of those who are responsible for data at the various lifecycle stages ${ }^{1}$.

Humphrey's understanding of research data management elevates data stewardship the responsibility and care for data - to the same level of importance as RDM's activities themselves. This two-part construction of RDM thus emphasizes not merely data preservation, access, or sharing, but the advanced knowledge and experience required to achieve these goals.

Humphrey's two-part construction of RDM was introduced to participants of CARL's RDM workshop, Introduction to Research Data Management Services, January $2013^{2}$. At this intensive workshop, Humphrey and other Canadian data librarians and preservationists introduced participants to RDM services through a rubric based on the four themes of collection, access, use, and preservation, which are widely used in the information profession and therefore mobilize existing expertise when considering data management in academic libraries. The workshop participants are now part of a growing number of research data management librarians in Canada.

\section{Research Data Management and Librarianship}

RDM's many facets - collection, access, use, and preservation - are aligned with the skill sets and aptitudes present in librarianship. In the US and UK, librarians have successfully promoted themselves as advocates for strong data management principles, data collection and metadata experts, RDM teachers and instructors, developers, research collaborators, policy leaders, and digital preservationists. In Canada, the foundational skills required to support these roles have been identified and promoted at the association level. In its assessment of core competencies for $21^{\text {st }}$

\footnotetext{
${ }^{1}$ Humphrey acknowledges the contribution Wendy Watkins made to his distinction between people and practice in the original text, a fact that should be mentioned here, given her longstanding work in Canadian data librarianship.

2 The developers and facilitators of the 2013 CARL RDM workshop were Pascal Calarco, Michelle Edwards, Alex Guindon, Chuck Humphrey, Steve Marks, Kathleen Shearer, and Wendy Watkins. Credit must be given to this group for helping to promote recent RDM initiatives in Canada.
} 
century librarians, CARL cites the growth of RDM as part of the evolution of the profession and highlights the aptitudes required to work within it:

[a]cademic librarians are also carving out new roles in support of research data management and preservation on campus . . . To be successful, librarians must seek out good partners. They must focus their attention on creating robust infrastructure for long-term data archiving, clean work flow tools and policies for describing, managing, sharing, and providing access to the data. Librarians will also be called upon to take an intermediary role in connecting multidisciplinary research communities and provide social software services. (5)

These aptitudes are made explicit in CARL's list of competencies, including knowledge of data management and institutional repositories within scholarly communication (6), developing partnerships and collaborations with stakeholders (7), and understanding leading practices for digital curation and preservation (8). Keralis, Stark, Halbert and Moen sampled predominantly librarians but also researchers and administrators in 2013, showing that the profession is confident it can play a role in RDM ("Research Data Management" 28; "DataRes Project Primary Survey"). When asked where RDM services and resources such as data management planning, training, and best practices should be located on campus, respondents consistently suggested the library as a key collaborator ("Research Data Management" 30). Furthermore, over $80 \%$ of respondents felt that "library schools or academic libraries should provide research data management certification opportunities for professional librarians and librarians in training," and over $60 \%$ felt that this opportunity should be afforded to researchers in all disciplines ("DataRes Project Primary Survey"). Librarians and their associations have identified that the competencies and values of the profession lend themselves well to research data management, that librarians can play a role in RDM, and that we can train ourselves and others on the principles of data stewardship.

\section{Research Data Management and the Library}

Until recently, research data management has been seen as the domain of a number of distinct roles in Canadian librarianship. Data librarians, who often liaise with Statistics Canada through the Data Liberation Initiative (Statistics Canada), have long been advocates of improved data access in the social sciences, data literacy, and professional development. Many science librarians have been introduced to RDM through their researchers' laboratory and field work. At the same time, digital preservationists, archivists, and developers have built the platforms and developed policies that make preservation and access to digitally born data possible. But as RDM emerges as a vital part of the research enterprise, academic libraries must remain cognizant of the fact that data management and data stewardship touch all the functions of the organization and interact with its campus stakeholders. The work of RDM draws on many functions and concerns in the library's organizational structure and succeeds by the knowledge and expertise of the librarians in these constituencies. 


\section{Policy Formulation and Interpretation}

While there is presently a data management policy gap among Canada's federal research councils and other stakeholders in the nation's research enterprise, new community-driven, needs-based oversight stands to become a significant RDM driver in Canada. Faced with the threat of a data deluge too large to properly manage with current resources, SSHRC, NSERC, CIHR, and CFI (collectively referred to as TC3+) authored the October 2013 consultation document, Capitalizing on Big Data: Toward a Policy Framework for Advancing Digital Scholarship in Canada. In it, they ask the nation's scholarly community to develop a collaborative framework that encourages data sharing and invests in digital infrastructure (Social Sciences and Humanities Research Council et al. 2). They also made three recommendations for RDM stakeholders that underscore the need for a holistic view of RDM's people, processes, and technology: establish a culture of research data stewardship based on existing structures and practices at Canadian and international institutions; coordinate stakeholder engagement among all research partners, including libraries; and develop funding and resource capacity (8-9).

TC3+'s framework is not an isolated example of recent data management policy development in Canada. Its proposal to establish a coordinated, funded research data initiative is aligned with the key recommendation to incorporate RDM within the nation's digital infrastructure delivered at the 2014 Digital Infrastructure Summit, hosted by the Leadership Council on Digital Infrastructure (LCDI) (8-12), and its concerns are similar to the Canadian Research Knowledge Network's (CRKN) Integrated Digital Scholarship Ecosystem (IDSE) project, which considers digital stewardship and data preservation as an emerging theme that can be addressed through collaborative, coordinated stakeholder engagement (Ridley and Pagotto 8). As well, in March 2014 CARL, with CRKN and Canadian regional academic library associations, initiated Project ARC, which "aims to lay the foundation for the implementation of a library-based research data management network in Canada" by helping institutions develop data management plans, and also focusing on the organizational structures required to build a Canadian RDM network and research data curation centre of expertise ("Project ARC"). TC3+'s policy framework, and initiatives like the Digital Infrastructure Summit, IDSE, and Project ARC stand to alter the Canadian research enterprise in favour of research data management and have the potential to create significant demand for RDM services inside and outside of the library. RDM librarians and academic library administrations must take part in, if not initiate, the conversation when RDM policy is formulated in order to lead the change that will happen on their campuses.

\section{Scholarly Communication}

Closely related to the policy formulation sphere is scholarly communication. Not all data can be shared immediately (e.g., data related to studies involving minors, intellectual property embargos or restrictions), and some researchers still prefer not to share their research data. To stay in accordance with research ethics board and industry 
obligations, and to meet funding agency and journal publication requirements, RDM librarians must stay informed of access and publication provisions that affect research on campus. The Draft Tri-Agency Open Access Policy (Natural Sciences and Engineering Research Council et al.) and PLOS's 2014 data sharing policy (Public Library of Science) are examples of key scholarly communication events that will affect RDM programmes.

\section{Collection Management}

RDM's relationship to collection management is substantial even if organizational considerations such as funding or resource availability mitigate data collection development at the local level. Conceptually, research data management requires an examination of the criteria researchers use to determine what to collect and what to preserve. While collection and appraisal methods are often aligned with disciplinespecific requirements, RDM librarians can benefit from the expertise of their collections librarians, who have experience managing resources within the constraints of cost, need, consortial obligations, and long-term value. RDM programmes, meanwhile, will benefit from the development of data collection policies. These policies help the library develop a collection through scoping criteria such as organizational priorities, researcher needs, and administrative constraints. Sarah Higgins summarizes these criteria, which include researcher and institutional obligations, the library's collection priorities, digital acquisition capabilities, as well as file transfer, management, and access considerations based on format and type (27). Even in the short term, the responsibility and cost associated with managing a data collection can have a significant impact on the RDM services of libraries of any size. It is incumbent on the RDM team to work with collections librarians to develop sound data collection policies and to avoid making promises that cannot be kept.

\section{Information Technology and Digital Preservation}

RDM is dependent on information technology. Our ability to collect, secure, clean, preserve, and provide access to data is mediated through IT. However, this dependency doesn't mean that RDM programmes on campuses with small or constrained IT budgets and resources are at a complete disadvantage. As the recent "DataRes" study showed, RDM programmes at even large American universities range from "robust, infrastructure-driven models to ad hoc support provided by individual librarians, depending on the resources and culture of a given institution" (Keralis, Stark, Halbert and Moen, "Research Data Management" 26). Each library's response to research data management, and especially its IT requirements, is unique and will be determined by resources at hand, organizational strategic plans, library staffing priorities, and consortial opportunities. Vital to RDM, however, is the role of the digital preservationist, whose understanding of technology and policy can reconcile researcher needs or desires with system capacity. According to CARL's core competencies assessment, the digital preservationist often understands "best practices for . . . digital documentation and research data in various formats" (8), has knowledge of institutional repository and database design and policy (9), and is familiar with other CARL-enumerated 
competencies such as database and project management.

Developing an IT and staffing strategy to provide the technology and supports that maintain an RDM programme is not always feasible in the short-to-medium term. The collaboration of Ontario academic libraries, however, shows that consortium experiences can mitigate IT gaps. Through Scholars Portal, the shared technological infrastructure of the Ontario Council of University Libraries (OCUL), Ontario university libraries maintain an instance of Dataverse, a data management service, and ODESI, the consortium's socio-economic data access portal; Scholars Portal also employs professional librarians and staff who lend support to the entire consortium. This model provides Ontario's academic libraries a shared infrastructure and knowledge base that supports RDM and the wider research enterprise as well as librarian professional development across the province.

\section{Liaison Services and Outreach}

A library's research data management programme cannot sustain itself without collaboration with its liaison librarians, whose work in reference and research services makes them crucial intermediaries between the library's services and its researcher community. Liaison librarians often have domain-specific expertise and a network of department-specific relationships that can spur development of an RDM programme by discovering important datasets, and they lend support with their subject knowledge. As Tracy Gabridge notes, liaison librarians have skill sets and expertise that enable them to support the analysis of discipline-specific deposit requirements, participate in data management planning, provide needed data literacy and research help, and to collect and disseminate data and contribute to the development of standards for data preservation (17-18). However, extending the liaison librarians' scope of duties to include research data management is not a quick process, for "there are clearly issues around resourcing and skills [for RDM]. There are patches of the appropriate skills; others need to be developed" (Cox and Pinfield 15). To ensure the effective delivery of an operational RDM programme, libraries should provide training "both on the digital literacy side (e.g., storage and preservation, access, metadata, etc.), and on the analytic side (e.g., appropriate algorithms, interpretation)" (Leadership Council for Digital Infrastructure 10). Such training requires organizational support and long term vision or risks becoming reactive professional development sessions that "tend to be responsive and opportunistic, rather than structured and carefully planned" (Auckland $60)$. RDM training for liaisons must be strategic, built upon librarians' existing knowledge, and engaged with the library's current operational capacities and long term plans.

Given the anticipated increase in demand for RDM services that libraries will face when the aforementioned TC3+ consultation on digital scholarship becomes policy, it is incumbent upon libraries to provide not only RDM training but also workload support for its liaisons, so they have the opportunity to embrace RDM as a core part of their collections and research support duties. This organizational shift will leverage and expand liaison librarians' knowledge in their subject areas and in information science to 
support the university's research enterprise.

\section{Campus Stakeholders: Researchers, Research Offices, and Research Ethics Boards}

The finest research data management programme is no success if it does not actually manage research data. Researcher support for the library's RDM programme is thus essential to its success, and the role researchers have in the management of their data is dependent on their knowledge and desire to collaborate and on the expertise and infrastructure the library can offer. The level of researcher involvement can also depend on their understanding of the library's ability to help them meet their RDM obligations. For example, the respondents to CLIR's 2012 survey of social science librarians at five American universities "reported feeling adrift when establishing protocols for managing their data and ... lacked the resources to determine best practices, let alone to implement them" (Jahnke and Asher 8), but few considered the library as a "locus for badly needed, real-time professional support" (16). Overcoming the gap between the perceived ability of the library to support the researcher's RDM needs and its actual ability to do so can be difficult, especially in Canada where research data management is still nascent. However, the real experience that the information profession has in areas such as metadata production and documentation, policy formulation and adherence, or digital preservation and discovery, makes collaboration with the library's RDM programme critical to the research enterprise. The development of collaborative models espoused by TC3+, the LCDI, and Project ARC cannot merely be approved by committee and enacted overnight. They also require relationship-building between the researcher and stakeholders such as the library to support the research itself.

Research data management also extends to administrative units that support the research enterprise. As well as information technology and enterprise resource management units on campus, librarians will find key stakeholders in research offices and research ethics boards. Staff in these offices typically liaise with researchers and work with partners to develop the university's research capacity. Research facilitators often help faculty complete grant applications and meet ongoing requirements through the life of the project and are therefore able to promote data management planning with the library at the start of the research lifecycle. These facilitators can help "ensure that those who will implement the [research data management] plan are involved as early as possible" (Erway 8). Research ethics board staff are also key stakeholders in RDM since they ensure that any research that involves humans is "conducted according to the highest ethical standards" (Canadian Institutes of Health Research, Natural Sciences and Engineering Research Council of Canada, and Social Sciences and Humanities Research Council of Canada 5). RDM librarians can work with ethics officers to ensure that the university and researchers maintain their ethical duty of confidentiality, which binds both the researcher and the school to "safeguard information entrusted to them and not misuse or wrongfully disclose it ... [and] support their researchers in maintaining promises of confidentiality" (58). Ethics board officers must also make certain that researchers meet their duty to secure data and information by "provid[ing] details to the REB [research ethics board] regarding their proposed 
measures for safeguarding information, for the full life cycle of information: its collection, use, dissemination, retention and/or disposal" (58). Like libraries, research offices and research ethics boards exist to support the research enterprise and therefore share some goals, among them the development of sound research practices. These allied offices can be proponents of the library's research data management services.

\section{Conclusion}

Research data management is becoming a significant part of the research enterprise in Canada. The awakening of funding agencies, researchers, and allied campus partners to the need for better stewardship of research data has expanded the role that academic libraries already play in the service provision of data collection, access, use, and preservation. Our expertise in RDM resides in all facets of the library's organizational structure, including cataloguing and metadata services, collections and acquisitions, information systems and digital projects, archives and preservation, and reference and research. Collaboration and stakeholder engagement is also vital for libraries to build robust services by partnering with researchers, research ethics boards, research offices, and peer libraries in consortia. The work of research data management is multi-faceted rather than singular, its required competencies are reflected in the current practice of many librarians, and its outcomes can improve the university research enterprise. To succeed is to collaborate among our peers in our libraries, and on our campuses.

\section{Works Cited}

"Project ARC." Canadian Community of Practice for Research Data Management in Libraries, 2014. Web. 24 May 2014. <http://data-carl-abrc.ca/project-arc/>.

Auckland, Mary. "Re-skilling for Research: An Investigation into the Role and Skills of Subject and Liaison Librarians Required to Effectively Support the Evolving Information Needs of Researchers." Research Libraries UK. Research Libraries UK, 2012. Web. 29 Apr. 2014. <http://www.rluk.ac.uk/wp-content/uploads/2014/ 02/RLUK-Re-skilling.pdf>.

Canadian Association of Research Libraries. "Core Competencies for 21st Century CARL Librarians." Canadian Association of Research Libraries, Canadian Association of Research Libraries, 2010. Web. 12 Feb. 2014. <http://www.carlabrc.ca/uploads/pdfs/core comp profile-e.pdf>.

---. "Research Data: Unseen Opportunities." Canadian Association of Research Libraries. Canadian Association of Research Libraries, 2009. Web. 12 Feb. 2014. $<$ http://carl-abrc.ca/uploads/pdfs/data mgt toolkit.pdf $>$. 
Canadian Institutes of Health Research, Natural Sciences and Engineering Research Council of Canada, and Social Sciences and Humanities Research Council of Canada. "Tri-Council Policy Statement: Ethical Conduct for Research Involving Humans." Panel on Research Ethics. Secretariat on Responsible Conduct of Research, Dec 2010. Web. 12 Feb. 2014. <http://www.pre.ethics.gc.ca/pdf/eng/ tcps2/TCPS 2 FINAL Web.pdf>.

Cox, Andrew M., and Stephen Pinfield. "Research Data Management and Libraries: Current Activities and Future Priorities." Journal of Librarianship and Information Science (2013): 1-18. Web. 18 Apr. 2014. <http://lis.sagepub.com/content/early/ 2013/06/28/0961000613492542>

Erway, Ricky. "Starting the Conversation: University-Wide Research Data Management Policy." OCLC Research. OCLC, 2013. Web. 10 Mar. 2014. < http://oclc.org/ content/dam/research/publications/library/2013/2013-08.pdf>.

Gabridge, Tracy. "The Last Mile: Liaison Roles in Curating Science and Engineering Data." Research Libraries Issues 265 (2009): 15-21. Web. 10 Mar. 2014. $<$ http://www.arl.org/bm doc/ rli-265-gabridge.pdf>

Higgins, Sarah. "The Lifecycle of Data Management." Managing Research Data. Ed. Graham Pryor. London: Facet Publishing, 2012. 17-46. Print.

Humphrey, Chuck. "Research Data Management I." Preserving Research Data in Canada. 2012. Web. 12 Feb. 2014.

$<$ http:// preservingresearchdataincanada.net/2012/12/13/research-datamanagement-infrastructure-i/>.

Jahnke, Lori, and Andrew Asher. "The Problem of Data: Data Management and Curation Practices Among University Researchers." The Problem of Data. Washington, DC: Council on Library and Information Resources, 2012. 3-32. Web. 29 Apr. 2014. <http://www.clir.org/pubs/reports/pub154/pub154.pdf>.

Keralis, Spencer D.C., Shannon Stark, Martin Halbert and William E. Moen. "DataRes Project Primary Survey." UNT Digital Library. University of North Texas Libraries, June 2012. Web. 10 Mar. 2014. <http:// digital.library.unt.edu/ark:/67531/metadc228265/>.

---. "Research Data Management in Policy and Practice: The DataRes Project." Research Data Management: Principles, Practices, and Prospects. Council on Library and Information Resources, 2013. 6-38. Web. 10 Mar. 2014. $<$ http://www.clir.org/pubs/reports/pub160/pub160.pdf>.

Leadership Council for Digital Infrastructure. "Summary Report: Digital Infrastructure Summit 2014.” DI Summit 2014. Leadership Council for Digital Infrastructure, 4 
Mar. 2014. Web. 20 Mar. 2014. < http://digitalleadership.ca/wpcontent/uploads/2014/02/Summary-Report-of-Summit-2014-Final-March-2014.pdf>.

Natural Sciences and Engineering Research Council, Social Sciences and Humanities Research Council, and Canadian Institutes of Health Research. "Draft Tri-Agency Open Access Policy." Natural Sciences and Engineering Research Council of Canada. Natural Sciences and Engineering Research Council, 2013. Web. 12 Feb. 2014. < http://www.nserc-crsng.gc.ca/ doc/Policies-Politiques/Tri-OA-PolicyPolitique-LA-Trois eng.pdf>.

Ontario Council of University Libraries. "Scholars Portal." Ontario Council of University Libraries. Ontario Council of University Libraries, 2013. Web. 15 Mar. 2014. $<$ http://ocul.on.ca/node/135>.

Public Library of Science. "PLOS Editorial and Publishing Policies." PLOS ONE. PLOS, 2014. Web. 14 Mar. 2014. < http://www.plosone.org/static/policies>.

Pryor, Graham, ed. Managing Research Data. London: Facet Publishing, 2012. Print.

Ridley, Michael, and Sabina Pagotto. "Preliminary Report: Canadian Research Knowledge Network Integrated Digital Scholarship Ecosystem (IDSE)." Integrated Digital Scholarship Ecosystem. Canadian Research Knowledge Network, 2014. Web. 1 May 2014. <http://crkn.ca/files/ crkn idse preliminary report march 2014 final.pdf>.

Social Sciences and Humanities Research Council, Canadian Institutes of Health Research, Natural Sciences and Engineering Research Council, and Canada Foundation for Innovation. "Capitalizing on Big Data: Toward a Policy Framework for Advancing Digital Scholarship in Canada." Social Sciences and Humanities Research Council. Social Sciences and Humanities Research Council, 2013. Web. 12 Feb 2014. <http://www.sshrc-crsh.gc.ca/aboutau sujet/publications/digital scholarship consultation e.pdf>.

Statistics Canada. "Data Liberation Initiative." Data Liberation Initiative. Statistics Canada, 2013. Web. 14 Mar. 2014. <http://www.statcan.gc.ca/dli-idd/dli-iddeng.htm>.

Witt, Michael. "Co-Designing, Co-Developing, and Co-Implementing an Institutional Data Repository Service." Journal of Library Administration 52.2 (2012): 172-188. Web. 12 Dec. 2013. 